\title{
Editorial
}

\section{Announcing the Journal of Retail \& Leisure Property bulletin board}

We are delighted to announce the launch of the Journal of Retail \& Leisure Property online bulletin board, which we hope will become an invaluable resource for business professionals wanting to keep up-to-date with the latest issues and industry trends in the retail and leisure property industry. This service is exclusive to Journal subscribers and provides a forum for them to discuss the latest developments and trends with their peers as well as share experience on the leading questions, ideas, problems and solutions of the day. It is by no means intended to replace the printed quarterly Journal but, rather, complement it with the ongoing debate fundamental to this fast moving industry.

Topics covered on the bulletin board include:

- Questions on specific problems, asking readers to share their experience and opinions of problems and potential solutions

- Seminars and conferences that will be of interest to this community

- Readers' thoughts on recent developments affecting the industry, such as an update to planning regulations or a landmark legal case

- Requests for sources of information, for instance on the availability of research in a specific area

- Vacancies open to senior practitioners

- 'Calls to arms' on key issues which it is felt the profession should be tackling more aggressively or in a different way

- Responses to articles published in the Journal

- A call for papers and research projects on specific topics to be published in future issues

Subscribers who wish to raise a question, respond to a point or simply join the debate, simply need to visit the following website and enter their details on the form:

http://www.henrystewart.com/retail_and_leisure_property/ board.html

You will then be automatically emailed your user name and password to register for access to the Journal of Retail \& Leisure Property bulletin board and will be able to access its contents 
and/or post a message immediately. Given the wealth of key issues currently affecting the industry this should make for some very interesting debate. We look forward to hearing from you.

Simon Beckett

Publisher

October 2005 